\title{
The Role of Empowerment in the Association between a Woman's Educational Status and Infant Mortality in Ethiopia: Secondary Analysis of Demographic and Health Surveys
}

\author{
Yibeltal Kiflie Alemayehu ${ }^{1,3}$, Katherine Theall ${ }^{1}$, Wuleta Lemma ${ }^{1}$, Kifle \\ Woldemichael Hajito ${ }^{1}$, Kora Tushune ${ }^{3}$
}

\begin{abstract}
BACKGROUND: Socioeconomic status at national, sub-national, household, and individual levels explains a significant portion of variation in infant mortality. Women's education is among the major determinants of infant mortality. The mechanism through which a woman's own educational status, over her husband's as well as household characteristics, influences infant mortality has not been well studied in developing countries. The objective of this study was to explore the role of woman's empowerment and household wealth in the association between a woman's educational status and infant mortality.

METHODS: The association between a woman's educational status and infant death, and the role of woman's empowerment and household wealth in this relationship, were examined among married women in Ethiopia through a secondary, serial cross-sectional analysis utilizing data on birth history of married women from three rounds of the Ethiopian Demographic and Health Survey. Univariate, bivariate, and multivariate analyses were conducted to examine the association between woman's education and infant death, and the possible mediation or moderation roles of woman empowerment and household wealth. RESULTS: Female education and empowerment were inversely associated with infant death. The results indicated mediation by empowerment in the education-infant death association, and effect modification by household wealth. Both empowerment and education had strongest inverse association with infant death among women from the richest households.

CONCLUSION: The findings suggest an important role of female empowerment in the education-infant death relation, and the complexity of these factors according to household wealth. Woman empowerment programs may prove effective as a shorter term intervention in reducing infant mortality. KEYWORDS: Woman, Education, Empowerment, Infant Mortality, Demographic and Health Survey, Social Determinants, Mediation, Moderation, Ethiopia
\end{abstract}

DOI:http://dx.doi.org/10.4314/ejhs.v25i4.9

\section{INTRODUCTION}

Reducing infant mortality has long been a global public health priority particularly for developing countries $(1,2)$. The fourth goal in the Millennium Development Goals (MDG) intends to reduce child mortality by two-third between the years
1990 and 2015. However, despite progress made by many countries, half of the world's nations are still behind their targets. In 2012, the expected number of infant deaths for every 1,000 live births ranged from as low as 1.7 in Luxemburg to as high as 117.4 in Sierra Leone $(3,4)$.

\footnotetext{
${ }^{1}$ Department of Global Community Health and Behavioral Sciences, School of Public Health and Tropical Medicine, Tulane University, New Orleans, USA

${ }^{2}$ Department of Epidemiology, College of Public Health and Medical Sciences, Jimma University, Jimma, Ethiopia ${ }^{3}$ Department of Health Services Management, College of Public Health and Medical Sciences, Jimma University, Jimma, Ethiopia

Corresponding Author: Yibeltal Kiflie Alemayehu, Email: kibeltal@gmail.com
} 
Ethiopia has shown remarkable progress on MDG4. Between 1990 and 2013, infant mortality rate (IMR) has decreased by $63.5 \%$ (4). However, the rate still remains at a very high level compared to the rest of the world. According to estimates from the most recent Ethiopia Demographic and Health Survey (EDHS), 59 out of 1,000 newborns die before their first birth day (5).

A significant portion of variation in infant mortality has been attributed to differences in socioeconomic status (SES) at national (6-9), subnational $(10,11)$ and household/individual levels (12-14). The WHO framework for action on social determinants of health considers access to material resources as one of the major mechanisms through which SES influences the distribution of health outcomes (15). Applied to survival of infants, this pathway requires both the availability of resources as well as the power to use already available resources, among women who are mostly responsible for the care of children. Studies on socioeconomic determinants of infant mortality, however, often focus on the role of household wealth and income rather than the SES of the mother herself or assign the SES of husbands to married women and their children (16). Such measures of SES might reflect women's true level of access to material resources in societies where women and men share equal power over household resources. However, in highly male dominant societies, like Ethiopia, where women have a limited say in household-level decisions (17); the appropriateness of such practices is questionable.

Studies on determinants of infant mortality in Ethiopia identified a number of proximate health behaviors and child care practices as drivers of infant mortality. Few studies that explored social determinants of childhood mortality also reported inverse association between a woman's level of education and childhood mortality (18-23). However, to our knowledge, there are no studies todate that examined the mechanism through which a woman's educational status over and above her husband's as well as household's characteristics influences infant mortality.

In this study, we examined: 1) the relationship between woman's education and infant death, 2) whether this association is mediated by woman's household-level empowerment and household wealth, and 3) whether the relation between woman's education and empowerment with infant death is moderated by household wealth. We adapted a conceptual framework from WHO's framework for action on social determinants of health (15) (Figure 1). The research adds to the body of knowledge on the pathways through which woman's education may lead to differential risks of infant mortality as well as information on the validity of assigning women and children with the SES of their husband in developing countries.

\section{MATERIALS AND METHODS}

A secondary serial cross-sectional analysis was conducted utilizing data from three rounds of EDHS administered in 2000, 2005, and 2011. EDHS is a regular survey conducted every five years by the Central Statistical Authority of Ethiopia. In each survey, data was collected from nationally representative samples of females aged 15 to 49 years selected through multistage sampling. The number of interviewed females was 15,367 in the 2000 EDHS, 14,070 in the 2005 EDHS, and 16,515 in the 2011 EDHS, making a total of 45,952 respondents $(5,24,25)$.

Among all female respondents, $16,267(35.4 \%)$ met the eligibility criteria of being married and having at least one birth during the five years period prior to date of interview. Data on five year birth history of eligible women was pooled from the survey datasets allowing the analysis to span the period 1996 to 2011 .

Measures: The primary outcome was the mother having experienced infant death-defined as having at least one infant death among births in five years prior to the survey. If any of the newborns within the five years period died before 12 completed months of life, the mother was considered to have had infant death. The primary exposure was maternal education. Educational status was assessed based on the highest category of school completed (no education, primary, secondary or higher level education) on an ordinal scale. 


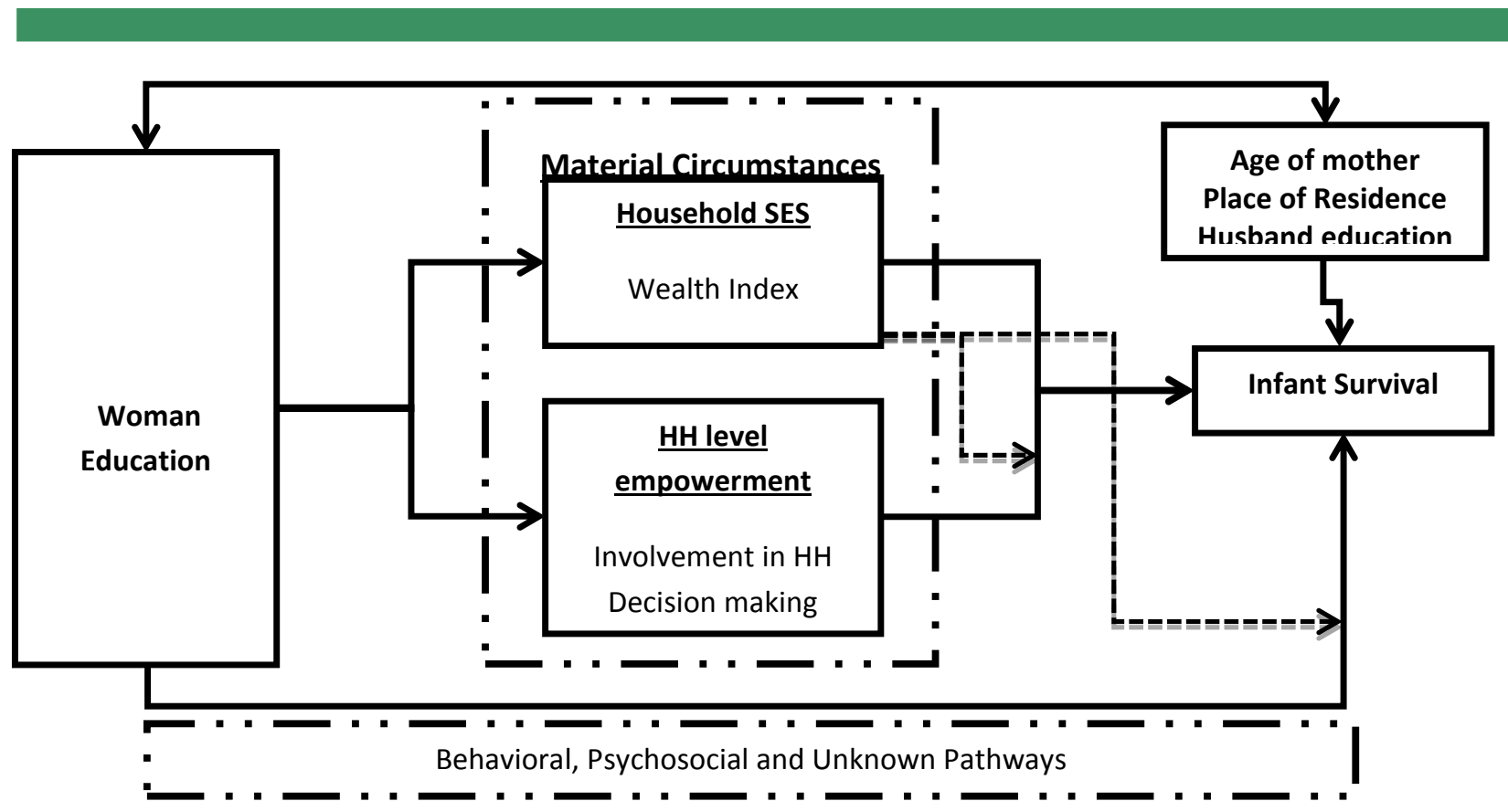

Figure 1: Woman's Education and Infant Survival, Conceptual Framework

Wealth index, categorized in quintiles to reflect cumulative living standard of a household in terms of relative wealth, was measured based on "easyto-collect data on a household's ownership of selected assets such as televisions and bicycles; materials used for housing construction, and types of water access and sanitation facilities". Women were categorized into five categories: poorest, poorer, middle, richer, and richest in terms of where their household falls in the distribution of the original sample (26).

Woman's empowerment, closely related to the concept of female autonomy introduced in the work of Dyson and Moore during the early 1980s (27), has been widely defined and measured in the social science literature during the past three decades (28-30). Despite contrasts made by some authors that view empowerment as a process of achieving autonomy, the concepts fundamentally share measures related to the freedom of a woman in making decisions affecting her own life (30). In our study, woman's empowerment was defined as the level of involvement (participation) of the woman in making decisions at the household level. We constructed a composite numeric variable based on three questions of involvement: involvement in decisions about own healthcare, major household purchases, and decisions about visiting relatives. The three items were found to be highly correlated and had an internal consistency Cronbach's alpha value of 0.844 . A woman was considered to be participating in decision making when household decisions are made jointly by husband and wife, primarily by wife or jointly by woman and someone else. Level of empowerment was then quantified as the number of decisions a woman participated with possible values ranging from 0 to 3 .

Sampling Weights: DHS in most countries including Ethiopia oversamples smaller regions and undersamples larger regions with the purpose of achieving representative sample size at subnational level while keeping total sample size manageable. As a result, it is recommended to weight cases during descriptive analysis of DHS data at national level (26). In this study, two additional non-self-weighting steps were involved: 1) we took only a subset of the original dataset based on the eligibility criteria of being married and having at least one birth in five years before the survey, and 2) we merged data from three rounds of surveys representing different population sizes because of population growth. Therefore, we adjusted the original woman's individual sample weight in a way that allowed maintaining the total number of cases equal between weighted and unweighted analyses while at the same time accounting for differences in the number of women represented by each sample in 
the final dataset. Weighting was applied only for descriptive analysis.

Data Analysis: Univariate, bivariate and multivariate analyses were conducted with SPSS version 22.0 for Windows (31). The association between experiencing infant death and a woman's educational status, level of empowerment, household wealth and potential confounders including age in years, type of residential area, and husband's educational status was examined using cross-tabulations and Chi-Square tests for independence. Multivariate logistic regression was used to control the effect of potential confounders and in testing mediation and moderation.

We hypothesized that:

0 a woman's own educational status is associated with infant mortality in Ethiopia;

0 this association is mediated by woman's empowerment and household wealth;

0 and the woman's education-infant mortality association and the mediation by woman's empowerment is moderated by household wealth.

The association between woman's education and experience of infant death was assessed by regressing experience of infant death on level of education. We then included potential confounders. Mediation analyses followed recommended steps $(32,33)$, whereby the relation between household-level woman empowerment and household SES is examined and if significant, included in the model, separately, to see if they attenuate the association between woman's education and experience of infant death. This mediated effect was also examined using the Sobel Test $(34,35)$. We assumed no confounding between the mediator and outcome as well as no interaction between the exposure and mediator. All potential confounding factors between the mediator and outcome were included in final models. Finally, stratified analysis was conducted to examine whether the impact of woman's education and empowerment on experience of infant death varied by wealth categories.

\section{RESULTS}

A total of 16,267 women with 25,472 births and $1,805(7.1 \%)$ infant deaths were included in the study. During the five year period preceding the surveys, 1,613(9.9\%), of the mothers had at least one infant death. The proportion of women who had at least one infant death decreased from $12.0 \%$ in the 2000 survey to $7.9 \%$ in the 2011 survey. Tables 1 and 2 show the proportion of mothers who had at least one infant death in five years preceding the survey disaggregated by different SES variables and potential confounders.

Table 1: Number of births and infant deaths by survey year, married women with at least one birth in five years before interview, Ethiopia DHS 2000, 2005 and 2011

\begin{tabular}{|c|c|c|c|c|c|c|c|c|c|c|c|c|}
\hline \multirow[b]{2}{*}{ Survey year } & \multirow[b]{2}{*}{ Time } & \multirow[b]{2}{*}{ \# of women } & \multicolumn{4}{|c|}{ Births in five years } & \multicolumn{4}{|c|}{ Infant deaths in five years } & \multicolumn{2}{|c|}{ Had infant death } \\
\hline & & & Min & Max & Mean & SD & Min & Max & Mean & SD & Number & $\%$ \\
\hline 2000 & $1996-2000$ & 4,617 & 1 & 5 & 1.59 & 0.65 & 0 & 5 & 0.14 & 0.40 & 556 & 12.0 \\
\hline 2005 & $2001-2005$ & 5,326 & 1 & 6 & 1.57 & 0.63 & 0 & 4 & 0.11 & 0.35 & 558 & 10.5 \\
\hline 2011 & $2007-2011$ & 6,324 & 1 & 5 & 1.55 & 0.64 & 0 & 3 & 0.09 & 0.32 & 499 & 7.9 \\
\hline Total & $1996-2011$ & 16,267 & 1 & 6 & 1.57 & 0.64 & 0 & 5 & 0.11 & 0.36 & 1,613 & 9.9 \\
\hline
\end{tabular}


The Role of Empowerment...

Table 2: Distribution of experience of infant death by woman, husband, and household characteristics, Ethiopia, 1996 to 2011 .

\begin{tabular}{|c|c|c|c|c|c|}
\hline \multirow[t]{2}{*}{ Variable } & \multirow[t]{2}{*}{ Category } & \multirow[t]{2}{*}{$\begin{array}{l}\text { Number of } \\
\text { women }\end{array}$} & \multicolumn{2}{|c|}{$\begin{array}{l}\text { Had at least one infant } \\
\text { death in previous five years }\end{array}$} & \multirow[t]{2}{*}{$\begin{array}{l}\text { Pearson Chi square test for } \\
\text { independence }\end{array}$} \\
\hline & & & Number & Percent & \\
\hline & All women & 16267 & 1613 & 9.9 & \\
\hline \multirow{3}{*}{$\begin{array}{l}\text { Woman's } \\
\text { educational level }\end{array}$} & No education & 12455 & 1330 & 10.7 & \multirow{3}{*}{$\begin{array}{l}\chi^{2}=39.9 \\
p<0.001\end{array}$} \\
\hline & Primary Education & 3172 & 246 & 7.8 & \\
\hline & Secondary or higher & 508 & 37 & 5.8 & \\
\hline \multirow[t]{2}{*}{ Empowerment } & Not empowered & 10615 & 1163 & 11.0 & \multirow{2}{*}{$\begin{array}{l}\chi^{2}=36.7 \\
p<0.001\end{array}$} \\
\hline & Empowered & 5652 & 450 & 8.0 & \\
\hline \multirow{4}{*}{$\begin{array}{l}\text { Number of } \\
\text { household } \\
\text { decisions woman } \\
\text { involved }\end{array}$} & None & 6070 & 674 & 11.1 & \multirow{4}{*}{$\begin{array}{l}\chi^{2}=38.7 \\
p<0.001\end{array}$} \\
\hline & One & 1879 & 204 & 10.9 & \\
\hline & Two & 2667 & 286 & 10.7 & \\
\hline & All (Three) & 5652 & 450 & 8.0 & \\
\hline \multirow[t]{5}{*}{ Wealth Index } & Poorest & 3409 & 351 & 10.3 & \multirow{5}{*}{$\begin{array}{l}\chi^{2}=7.5 \\
p=0.112\end{array}$} \\
\hline & Poorer & 3508 & 332 & 9.5 & \\
\hline & Middle & 3601 & 389 & 10.8 & \\
\hline & Richer & 3339 & 328 & 9.8 & \\
\hline & Richest & 2411 & 214 & 8.9 & \\
\hline \multirow[t]{7}{*}{$\begin{array}{l}\text { Age in 5-year } \\
\text { groups }\end{array}$} & $15-19$ & 803 & 111 & 13.8 & \multirow{7}{*}{$\begin{array}{l}\chi^{2}=33.4 \\
p<0.001\end{array}$} \\
\hline & $20-24$ & 3209 & 361 & 11.2 & \\
\hline & $25-29$ & 4571 & 449 & 9.8 & \\
\hline & $30-34$ & 3212 & 300 & 9.3 & \\
\hline & $35-39$ & 2558 & 200 & 7.8 & \\
\hline & $40-44$ & 1299 & 128 & 9.9 & \\
\hline & $45-49$ & 615 & 64 & 10.4 & \\
\hline \multirow[t]{2}{*}{$\begin{array}{l}\text { Type of place of } \\
\text { residence }\end{array}$} & Urban & 1623 & 123 & 7.6 & \multirow{2}{*}{$\begin{array}{l}\chi^{2}=10.7 \\
p=0.001\end{array}$} \\
\hline & Rural & 14644 & 1490 & 10.2 & \\
\hline \multirow[t]{3}{*}{$\begin{array}{l}\text { Husband's Highest } \\
\text { educational level }\end{array}$} & No education & 9299 & 988 & 10.6 & \multirow{3}{*}{$\begin{array}{l}\chi^{2}=13.3 \\
p=0.001\end{array}$} \\
\hline & Primary Education & 5412 & 498 & 9.2 & \\
\hline & Secondary or higher & 1152 & 121 & 8.2 & \\
\hline \multirow[t]{3}{*}{$\begin{array}{l}\text { Period covered by } \\
\text { the survey }\end{array}$} & 1996 to 2000 & 4617 & 556 & 12.0 & \multirow{3}{*}{$\begin{array}{l}\chi^{2}=54.9 \\
p<0.001\end{array}$} \\
\hline & 2001 to 2005 & 5326 & 558 & 10.5 & \\
\hline & 2007 to 2011 & 6324 & 499 & 7.9 & \\
\hline
\end{tabular}


Association between Woman's Educational Status and Infant Death: Woman's educational status was significantly associated with experience of infant death both on crude analysis (Model 1 in Table 3) and after controlling for age, type of residential area and husband's educational status, with $17 \%$ lower likelihood of experiencing infant death for each level increase in educational status $(\mathrm{OR}=0.83$, 95\%CI: 0.73, 0.95). A mother who completed high school had $31 \%$ lower risk of experiencing infant death compared to a mother with no education (Model 2 in Table 3).

Mediation Analysis 1: The role of women's empowerment: The mediation role of woman's empowerment in the association between woman's education and experience of infant death was assessed by first examining whether woman's empowerment was associated with both woman's education and experience of infant death. Woman's empowerment was found to be associated with woman's educational level $(\mathrm{B}=0.231$, $\mathrm{P}$-value $<0.001)$ after accounting for age, type of place of residence and husband's education.

Controlling for these potential confounders and the direct effect of woman's education, woman's empowerment was significantly and inversely associated with experience of infant death (Model 3 in Table 3). The inclusion of woman's empowerment in this model attenuated the association between woman's eduation and experience of infant death. Between Model 2 and Model 3, the effect term (Beta) changed from 0.184 (Model 2 in Table 3) to -0.160 (Model 3 in table 3 )-a $13 \%$ reduction in the initial association. Both woman's education and empowerment were associated with experiencing infant death in the final model. The observed partial mediation of the effect of woman education by woman empowerment was found to be statistically significant (Sobel test statistic $=-4.63, \quad \mathrm{P}$ value $<0.001)$.

Mediation Analysis 2: The role of household SES (Wealth index): We regressed household wealth (wealth index as ordinal variable) on woman's education and found statistically significant association after controlling for the effects of age, type of place of residence and husband's educational level $(B=0.159$, $p$-value $<0.001$ ). However, there was no statistically significant association between wealth index and experiencing infant death when the effects of age, type of place of residence, husband's educational level and the direct effect of woman's educational level are controlled for $(\mathrm{B}=0.016$, $\mathrm{p}$-value $=0.455)$ (Model 4 in table 3).

Effect modification by household wealth: We conducted stratified analysis, by wealth index, to examine whether the direct effect of woman's education and the effect of empowerment on experiencing infant death were modified by household wealth. Differential effects were observed across levels of wealth (Models 5, 6, 7, 8, and 9-full models not presented). The association between woman's education and infant death was not statistically significant among women from relatively poor households; however, stronger inverse associations were observed among women from relatively rich households. Similarly, the association between woman's empowerment and infant death was weakest among mothers from poorer households and strongest among those from richer households (Table 4).

\section{DISCUSSION}

Some studies have examined the effect of maternal education on infant mortality in developing countries (12-14). The mechanism through which woman education impacts on infant mortality and how this mechanism interacts with availability of resources at household level has not been adequately examined. This study begins to close this gap by examining the validity of a hypothesized pathway involving woman's education, woman's empowerment, household wealth and infant death. The results support the hypothesis that a woman's education level is inversely associated with infant death and that this association is partly mediated by woman's empowerment. Furthermore, the findings suggest that the effects of both woman's education and empowerment on infant death are moderated by household wealth. Figure 2 presents a revised theoretical framework based on our findings.

Women hold primary responsibility for the care of children throughout the world (36). Accomplishing this responsibility to achieve better health outcomes for their children requires both the availability of resources in a household and a certain level of control over available resources. In 
Table 3: Factors associated with experience of infant death: tests for mediation role of woman empowerment and wealth index, Ethiopia, 1996 to 2011

\begin{tabular}{|c|c|c|c|c|c|c|c|c|c|c|c|c|}
\hline \multirow[t]{3}{*}{ Independent Variables included } & \multicolumn{3}{|c|}{ Model 1} & \multicolumn{3}{|c|}{ Model 2} & \multirow{2}{*}{\multicolumn{3}{|c|}{$\begin{array}{c}\text { Model 3 } \\
\text { Mediation analysis } \\
\text { (Empowerment) }\end{array}$}} & \multirow{2}{*}{\multicolumn{3}{|c|}{$\begin{array}{c}\text { Model } 4 \\
\text { Mediation analysis } \\
\text { (Wealth) }\end{array}$}} \\
\hline & \multicolumn{3}{|c|}{ Crude association } & \multicolumn{3}{|c|}{ Control for potential confounders } & & & & & & \\
\hline & $\mathrm{B}$ & SE & P-Value & $\mathrm{B}$ & SE & P-Value & $\mathrm{B}$ & SE & P-Value & $\mathrm{B}$ & SE & P-Value \\
\hline Constant & -2.189 & 0.029 & .000 & -2.059 & 0.237 & .000 & -1.931 & 0.239 & .000 & -2.137 & .259 & .000 \\
\hline Woman's educational status & -0.278 & 0.053 & .000 & -0.184 & 0.066 & .005 & -0.160 & 0.066 & .016 & -.186 & .066 & .005 \\
\hline & & & & 0.235 & 0.100 & & 0.228 & 0.100 & & .255 & .103 & .013 \\
\hline Rural residence & & & & -0.096 & 0050 & .018 & -0.088 & 0050 & .023 & -100 & 050 & 045 \\
\hline Husband educational status & & & & & & .054 & & & .076 & & & \\
\hline Woman empowerment & & & & & & & -0.099 & 0.021 & .000 & & & \\
\hline
\end{tabular}

this study, we tested which one of these factors is influenced by a woman's educational status in the pathway to reduce the risk of infant death. In this regard, we found that the association between woman's education and infant death is mediated by woman's empowerment but not by household wealth. This suggests that an increase in a woman's own education may decrease the risk of infant death, presumptively because of the power it gives her in making household decisions rather than the additional wealth it brings to the household. This may indicate the potential of empowering women to improve infant survival through maximal use of already existing household resources in a developing country setting.

The framework for social determinants of health from the WHO considers access to material resources as one of the major pathways through which SES affects health (15). In social determinants research, it is a common practice to assign married women and their children with SES of their husband or their household (16). For material circumstances pathway in the association between SES and health outcomes, such measures make the assumption that women have control over household resources. However, woman's education and empowerment status rather than wealth index and husband education are found to be important determinants of infant death in our study. Our findings suggest that the practice of assigning women with husband or household SES may not be appropriate in the context of Ethiopia and similarly in male dominated societies where women have limited control over household resources (17). 
Table 4: Direct effects of woman education and woman empowerment on experience of infant death: Stratified Analysis, Ethiopia, 1996 to 2011

\begin{tabular}{|c|c|c|c|c|c|}
\hline \multirow[t]{2}{*}{ Wealth Index } & \multirow[t]{2}{*}{ Covariate } & \multicolumn{2}{|c|}{ OR $(95 \% \mathrm{CI})$} & \multirow[b]{2}{*}{ Upper limit } & \multirow{2}{*}{ Sig. } \\
\hline & & OR & Lower limit & & \\
\hline \multirow{4}{*}{$\begin{array}{l}\text { The poorest } \\
\text { (From model } 5^{*} \text { ) } \\
\text { The poorer } \\
\left(\text { From model } 6^{*} \text { ) }\right.\end{array}$} & Woman Education & 1.024 & 0.735 & 1.426 & 0.890 \\
\hline & Woman Empowerment & 0.913 & 0.837 & 0.996 & 0.039 \\
\hline & Woman Education & 1.155 & 0.850 & 1.570 & 0.357 \\
\hline & Woman Empowerment & 0.965 & 0.877 & 1.061 & 0.461 \\
\hline \multirow{2}{*}{$\begin{array}{l}\text { The middle } \\
\text { (From model } 7^{*} \text { ) }\end{array}$} & Woman Education & 0.865 & 0.647 & 1.155 & 0.324 \\
\hline & Woman Empowerment & 0.977 & 0.892 & 1.070 & 0.621 \\
\hline \multirow{2}{*}{$\begin{array}{l}\text { The richer } \\
\text { (From model } 8^{*} \text { ) }\end{array}$} & Woman Education & 0.785 & 0.595 & 1.037 & 0.088 \\
\hline & Woman Empowerment & 0.829 & 0.754 & 0.913 & 0.000 \\
\hline \multirow{2}{*}{$\begin{array}{l}\text { The richest } \\
\text { (From model 9*) }\end{array}$} & Woman Education & 0.705 & 0.546 & 0.910 & 0.007 \\
\hline & Woman Empowerment & 0.871 & 0.773 & 0.981 & 0.023 \\
\hline
\end{tabular}

"Models 5-9 (full models not presented) are versions of model 3, where the effects of age, residence, and husband education are controlled, stratified by household wealth.

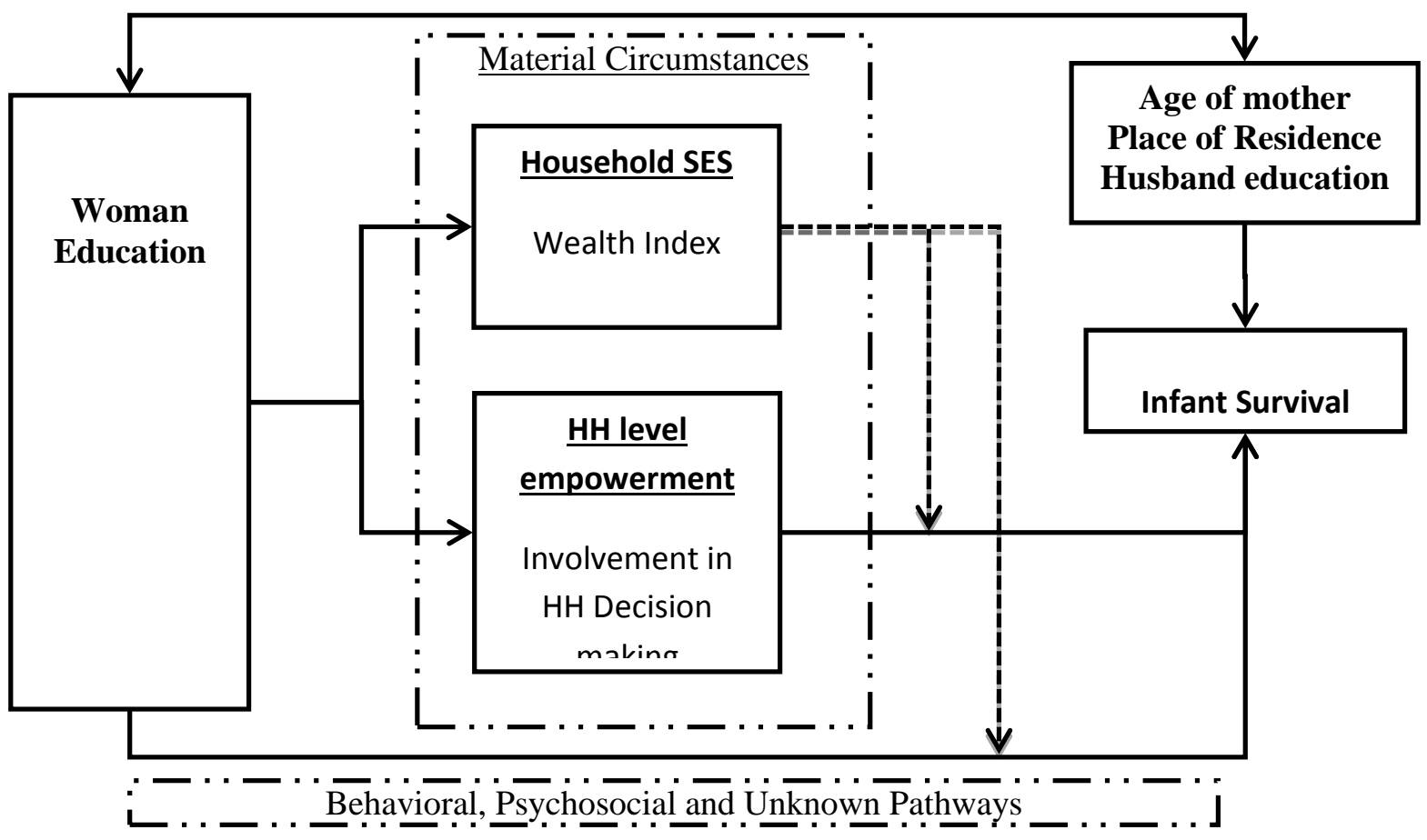

Figure 2: Women Education and Infant Survival, Revised Conceptual Framework

Household wealth modified both the direct and empowerment-mediated effects of woman's education on infant death. Both woman's education and empowerment had the greatest impact on risk of infant death among households with more resources. This finding supports the portion of WHO's conceptual framework for social determinants of health that assumes mediation by access to material resources in the association between SES and Health outcomes (15). 
This study has two important limitations. First, because of the cross-sectional nature of DHS data, all the associations we reported lack temporal relationships. While a woman's education and empowerment status at the time of interview in most cases could reflect her status before births in the five years period preceding the interview, there is also some possibility that women change their educational level and/or their empowerment status. However, we believe that the extent of potential bias is small as our study participants (married women who had at least one birth during the preceding five years) are expected to have more stable educational level than what we would have expected from younger single women who spend most of their time in schools.

The other limitation of our study is related to the possibility of clustering. People living in the same area share some of the major determinants of infant mortality including access to water, sanitation and healthcare (37). As a result, we expect a certain level of clustering in our data. However, because of the lack of comprehensive geographic data, we were limited to single level analysis without testing whether a multilevel model was appropriate.

In conclusion, in Ethiopia, woman's education is inversely associated with infant death, and this association is mediated by a mother's household-level empowerment status and moderated by household wealth. While maintaining the long term vision of women's education helps to sustainably reduce infant mortality, empowering women at household level has the potential to improve material circumstances and child health outcomes in the short term. Improving household wealth is an important condition but not sufficient to reduce infant mortality by itself; woman's power plays vital role in translating available resources into child health outcomes. Poverty reduction measures should therefore be complemented by woman education and empowerment efforts which in return can contribute to infant survival.

\section{REFERENCES}

1. United Nations, 2000. United Nations Millennium Declaration. The United Nations General Assembly.
2. WHO, 1978. Declaration of Alma-Ata. International Conference on Primary Health Care; 1978; Alma-Ata, USSR.

3. United Nations, 2012. Infant mortality rate (0-1 year) per 1,000 live births.

4. United Nations, 2015. Millennium Development Indicators: The Official United Nations Site for the MDG Indicators [Internet]. United Nations. 2015 [cited 20 April 2015]. Available from: http://mdgs.un.org/unsd/mdg/Data.aspx

5. Central Statistical Agency, ICF International. Ethiopia, 2012. Demographic and Health Survey 2011.

6. Hajizadeh M, Nandi A, Heymann J. Social inequality in infant mortality: what explains variation across low and middle income countries? Social science \& medicine, 2014;101:36-46. PubMed PMID: 24560222.

7. Hales S, Howden-Chapman P, Salmond C, Woodward A, Mackenbach J. National infant mortality rates in relation to gross national product and distribution of income. Lancet, 1999;354(9195):2047. PubMed PMID: 10636372.

8. Lynch J, Smith GD, Hillemeier M, Shaw M, Raghunathan T, Kaplan G. Income inequality, the psychosocial environment, and health: comparisons of wealthy nations. Lancet, 2001;358(9277):194-200. PubMed PMID: 11476836.

9. Wagstaff A. Socioeconomic inequalities in child mortality: comparisons across nine developing countries. Bulletin of the WHO, 2000;78(1):19-29. PubMed PMID: 10686730. Pubmed Central PMCID: 2560599.

10. Jaramillo-Mejia MC, Chernichovsky D, JimenezMoleon JJ. [Regional disparities in infant mortality in Colombia]. Revista peruana de medicina experimental y salud publica, 2013;30(4):551-9. PubMed PMID: 24448929. Brechas regionales de la mortalidad infantil en Colombia.

11. Adedini SA, Odimegwu C, Imasiku EN, Ononokpono DN, Ibisomi L. Regional Variations in Infant and Child Mortality in Nigeria: A Multilevel Analysis. Journal of biosocial science, 2014;10:1-23. PubMed PMID: 24411023.

12. Hosseinpoor AR, Van Doorslaer E, Speybroeck N, Naghavi M, Mohammad K, Majdzadeh R, et al. Decomposing socioeconomic inequality in infant mortality in Iran. International journal of epidemiology, 2006;35(5):1211-9. PubMed PMID: 16987848.

13. Caldwell J, McDonald P. Influence of maternal education on infant and child mortality: levels and causes. Health policy and education, 1982;2(34):251-67. PubMed PMID: 10256648. 
14. Pena R, Wall S, Persson LA. The effect of poverty, social inequity, and maternal education on infant mortality in Nicaragua, 1988-1993. American journal of public health, 2000;90(1):64-9. PubMed PMID: 10630139. Pubmed Central PMCID: 1446115.

15. Solar O., Irwin A. A conceptual framework for action on the social determinants of health. Social Determinants of Health Discussion Paper 2 (Policy and Practice). 2010.

16. Galobardes B, Shaw M, Lawlor DA, Smith GD, Lynch J. Indicators of Socioeconomic Position. In: Oakes JM, Kaufman JS, editors. Methods in social epidemiology. San Francisco, Calif.: Jossey-Bass; 2006:47- 85.

17. Ethiopian Society of Population Studies. Gender Inequality and Women's Empowerment: In-depth Analysis of the Ethiopian Demographic and Health Survey 2005, 2008.

18. Dube L, Taha M, Asefa H. Determinants of infant mortality in community of Gilgel Gibe Field Research Center, Southwest Ethiopia: a matched case control study. BMC public health, 2013;13:401. PubMed PMID: 23621915. Pubmed Central PMCID: 3644261.

19. Lindstrom DP, Berhanu B. The effects of breastfeeding and birth spacing on infant and early childhood mortality in Ethiopia. Social biology, 2000;47(1-2):1-17. PubMed PMID: 11521450.

20. Susuman AS. Child mortality rate in ethiopia. Iranian journal of public health, 2012;41(3):9-19. PubMed PMID: 23113145. Pubmed Central PMCID: 3481706.

21. Kumar PP, File G. Infant and Child Mortality in Ethiopia: A Statistical Analysis Approach. Ethiop J Educ \& Sc, 2010;5(2):51 - 7.

22. Dejene T, Girma E. Social determinants of underfive mortality in Ethiopia: Event history analysis using evidence from Ethiopian Demographic and Health Survey. Health, 2013;5(5):879-85.

23. Girma B, Berhane Y. Children who were vaccinated, breast fed and from low parity mothers live longer: a community based case-control study in Jimma, Ethiopia. BMC public health, 2011;11:197. PubMed PMID: 21453455. Pubmed Central PMCID: 3084172.

24. Central Statistical Agency, ORC Macro, 2001. Ethiopia Demographic and Health Survey 2000.

25. No Name. Ethiopia 2005: results from the demographic and health survey. Studies in family planning, 2007;38(2):135-40. PubMed PMID: 17642415.
26. Measure DHS, ICF International, 2013. Demographic and Health Surveys Methodology: Standard Recode Manual for DHS 6.

27. Dyson T, Moore M. On Kinship Structure, Female Autonomy, and Demographic Behaviour in India. Population and Development Review. 1983;9(1). Epub 60.

28. Basu AM. Culture, the status of women, and demographic behaviour. Oxford England Oxford ; New York: Clarendon Press; Oxford University Press; 1992. xvii, 265 p. p.

29. Kabeer N. Reflections on the Measurement of Women's Empowerment. In: Sisask A, editor. Discussing Women's Empowerment - Theory and Practice 2001:17 - 57.

30. Mason KO. Measuring Women's Empowerement: Learning from Cross-National Research. In: Narayan D, editor. Measuring Empowerment: Cross Disciplinary Perspectives. Washington DC: The World Bank; 2005: 89 - 102.

31. IBM Corp. Released 2013. IBM SPSS Statistics for Windows, Version 22.0. Armonk, NY: IBM Corp; 2013.

32. MacKinnon DP, Fairchild AJ, Fritz MS. Mediation analysis. Annual review of psychology, 2007;58:593-614. PubMed PMID: 16968208. Pubmed Central PMCID: 2819368.

33. Baron RM, Kenny DA. The moderator-mediator variable distinction in social psychological research: conceptual, strategic, and statistical considerations. Journal of personality and social psychology, 1986;51(6):1173-82. PubMed PMID: 3806354.

34. Sobel ME. Asymptotic Confidence Intervals for Indirect Effects in Structural Equation Models. Sociological Methodology, 1982;13:290-312.

35. Preacher KJ. Calculation for the Sobel Test: An interactive calculation tool for mediation tests 2014 [updated 2010; cited 201410 April 2014]. Available http://quantpsy.org/sobel/sobel.htm

36. Treas J, Drobni*c S. Dividing the domestic : men, women, and household work in cross-national perspective. Stanford, Calif.: Stanford University Press; 2010. xv, 261 p. p.

37. Muldoon KA, Galway LP, Nakajima M, Kanters S, Hogg RS, Bendavid E, et al. Health system determinants of infant, child and maternal mortality: A cross-sectional study of UN member countries. Globalization and health, 2011;7:42. PubMed PMID: 22023970. Pubmed Central PMCID: 3247841. 